\title{
Minimally invasive proximal cavities restored with a hybrid, flowable and low-shrinking composite: effect of marginal ridge preservation on failure pattern
}

\author{
Ah Ra Cho, Ivo Krejci and Tissiana Bortolotto* \\ Division of Cariology and Endodontology, University Clinic of Dental Medicine, Faculty of Medicine, University of Geneva, 1, rue Michel-Servet, 1211, \\ Genève 4, Switzerland
}

${ }^{\star}$ Corresponding author: Tissiana Bortolotto, Division of Cariology and Endodontology, University Clinic of Dental Medicine, Faculty of Medicine, University of Geneva, 1, rue Michel-Servet, 1211, Genève 4, Switzerland; Tel: +41 (0)22 37941 77; E-mail: Tissiana.Bortolotto@unige.ch

Received: April 09, 2020; Accepted: April 16, 2020; Published: April 25, 2020

\begin{abstract}
Objectives: The present study assessed the restorative potential of silorane, flowable or hybrid-based composite resin for the ultraconservative occlusal fossa technique.

Materials and methods: Thirty-two intact human molars received in the proximal ridge a $1 \times 2 \times 4$ mm size occlusal cavity leaving the enamel ridge intact. The bur was then tilted at $30^{\circ}$ alongside enamel ridge to simulate a typical carious cavity. After enamel etching and application of adhesive system, cavities were filled with three composites and then, a $0.8 \mathrm{~mm}$ diameter hole was prepared beneath the proximal contact area to simulate an incipient enamel carious lesion. Restored molars were submitted to mechanical loading. The adhesive interfaces before and after loading were evaluated with SEM. The fracture test was performed on fatigued molars and maximum breaking loads were recorded.
\end{abstract}

Results: The hybrid and silorane composites showed, after the fatigue test, higher percentages of continuous margins ( $81 \pm 12$ and $75 \pm 17$, respectively) in comparison to flowable material $(53 \pm 24)$. Similar fracture resistance was recorded by the three composite types, but significantly lower than the fracture resistance of the non-restored group. Nevertheless, a trend to a ductile behaviour, i.e. better capacity for elastic deformation, was observed in the group restored with the hybrid composite.

Conclusions: Minimally invasive occlusal restorations with marginal ridge preservation and simulated proximal decay can be efficiently restored with hybrid and low shrinking composites. The flowable composite might not be indicated in this cavity type, in view of the marginal degradation observed after the fatigue test.

Clinical relevance: The ultraconservative occlusal fossa restorations realized with hybrid composite or silorane, may be a valid alternative to conventional class II restorations.

Keywords: Occlusal fossa technique, modified class II cavities, interproximal carious lesions, minimal invasive, marginal adaptation, resin composite, marginal ridge preservation.

\section{Introduction}

For many years, Black's idea of extension for prevention [1] has been an important principle in dentistry. In this approach, caries lesions are surgically removed and the restorative margins extended to areas enabling an easy cleaning. But in recent years, this idea has been considered outmoded due to an increased understanding of caries process and the development of restorative adhesive materials. A more conservative concept called 'minimally invasive dentistry' has been progressively introduced into the dental profession. In this philosophy, the preservation of natural tooth structure is paramount as no actual restorative material can replace enamel and dentine at a hundred percent.

The conventional class II cavity for the treatment of interproximal caries lesions, even if it is a commonly used restorative procedure, is particularly destructive because of the indirect approach to access the lesion. The marginal ridge removal undermines tooth resistance [2] and there is a high risk of iatrogenic damage to adjacent tooth during preparation [3-5]. In addition, the technical difficulties to correctly shape restorations in the proximal region [6] and the large perimeter of the restoration most likely lead to its long-term failure. To avoid these disadvantages, several attempts were made to restore proximal caries lesions.

Remineralization with fluoride and proximal sealing may be the most conservative ways to treat incipient caries or small proximal lesions in combination with limited demineralization areas in the enamel wall in patients with a rather low caries activity [7]. Thanks to a better understanding of the carious process, it is widely accepted that, in many cases, demineralized enamel lesions without cavitation can be remineralized with fluoride [8]. In respect to proximal sealing, this technique consists of the infiltration of a low-viscosity resin into demineralized enamel to reduce microporosities and improve mechanical 
support [8]. Nevertheless, both techniques, i.e. fluoride application and proximal sealing, are indicated when caries is confined to enamel.

In cases where caries has involved also dentinal tissue, a restorative approach is necessary and several techniques such as minibox, tunnel and ultraconservative occlusal fossa, are currently available. The minibox or vertical slot technique [9], in which the marginal ridge is removed whilst preserving as much tooth tissue as possible, is a more conservative approach than conventional class II cavity. Another attempt to even more conservative approach is the tunnel technique allowing partial preservation of marginal ridge. Nevertheless, none of the suggested conservative intervention modalities gave satisfactory results, especially when glass-ionomer cement was used as restorative material. One review [10] stated that both efficiency in caries removal and marginal ridge strength were reduced in glass-ionomer tunnel restorations with an annual failure rate of $7-10 \%$. Another study [11] found that glass-ionomer tunnel restoration was more damaging than minimal class II composite restoration as evidenced by the stiffness, load at fracture and proximity of the restoration to the pulp.

Finally an ultraconservative occlusal fossa $[9,12]$ or extended sealing [13] technique was suggested in which dentin caries were removed through a small occlusal cavity while preserving the marginal ridge. Other names such as 'internal preparation', 'partial tunnel,' 'blind tunnel' and 'class I tunnel' have also been used to describe this technique [9]. These procedures avoid the disadvantages of other techniques described above and can be considered the most conservative alternative to conventional class II approach. While some studies observed more risk of failure, mainly due to fracture of the marginal ridge [7,10,11,14], for tunnel or occlusal fossa restorations compared to those of conventional class II, adhesive restorative materials can often re-establish support for fragile enamel marginal ridge $[9,15]$ especially when the proximal carious lesion is more than $2.5 \mathrm{~mm}$ below the crest [16]. Moreover, low-shrinkage composite materials might limit weakening of enamel ridge during restorative work due to the generation of lower contraction stresses during polymerization.

Only a few studies evaluated the occlusal fossa procedure $[7,17,18]$ and none of them had the same approach as the present study since they were in-vivo trials and cavities were restored with glass ionomer material. Findings of these studies were very diverse. In-vivo studies reported failure rates of 0 to 10 per cent per year in 2 to 7 years. The comparison of results between tunnel and occlusal fossa restorations was also contradictory; one study reported higher failure rates of occlusal fossa restorations to those of tunnel restorations [18] and another similar study reported the exact contrary [19] but 5 years after, the same author reported that there was no difference in failure rate between two types of restorations [7]. However, it is interesting to see that in the above mentioned limited invivo trial with 20 restorations and a mean final assessment time of 23.3 months, no collapse of the marginal ridge was observed while it was thought to be a common occurrence. This fact gives clinical potential to this technique [17]. Another study concluded that maintaining the residual tooth 'bridge' in the form of proximal ridge has the potential to limit tooth deformation [20].

For the occlusal fossa procedure, an alternative material to glass ionomer could be resin composites with different mechanical properties (Table 1). Silorane and flowable composite have similar elastic modulus but develop different contraction forces whilst hybrid composite has a higher elastic modulus with contraction forces within the range of the two other materials. All three materials present a high filler load by weight to ensure mechanical strength of the restorations and could be potentially used for the definitive restoration of proximal incipient carious lesions. And given the fact that there is no available technique to reproduce artificial carious lesions through the enamel, in our study the proximal carious lesions were simulated by a cavity, drilled into the proximal wall, as this was the only way to simulate proximal enamel demineralization. This method might demonstrate if restorative procedures with different resin composites are capable to resist fatigue test and provide sufficient mechanical support to the restored teeth, even in cases in which enamel substance is eliminated beneath proximal contact area of the marginal ridge.

Therefore, the aim of this study was to assess the restorative potential of a silorane, flowable or hybrid-based composite resin for the ultraconservative occlusal fossa technique. The first null hypothesis was that there would be no difference in marginal adaptation amongst molars restored with different materials, before and after cyclic mechanical loading. The second null hypothesis was that there would be no difference in the marginal ridge fracture resistance amongst different experimental groups (molars restored with different materials).

\section{Materials and methods}

Thirty-two caries-free human third molars were used for this study and randomly assigned to four equal experimental groups. Group description and material properties are detailed in Tables 1 and 2 .

Each tooth received in the proximal ridge an occlusal cavity of dimension $1 \times 2 \times 4 \mathrm{~mm}$ (Fig. 1a) prepared with a $0.9 \mathrm{~mm}$ diameter and 80 $\mu \mathrm{m}$ diamond-coated cylinder bur (Intensiv SA, Grancia, Switzerland) mounted on a red contra-angle handpiece leaving the whole enamel ridge intact. The bur was then tilted at $30^{\circ}$ alongside enamel ridge to simulate a typical carious cavity (Fig. 1b). The marginal edge was bevelled with a $25 \mu \mathrm{m}$ flame-shaped bur (Intensiv SA, Grancia,

Table 1: Material Properties (information provided by manufacturers)

\begin{tabular}{|c|c|c|c|}
\hline Material & Elastic modulus [GPa] & Filler load by weight [\%] & Contraction force $[\mathrm{Kg}]$ \\
\hline Flowable & 10.5 & 81 & 4.2 \\
\hline Hybrid & 22.0 & 92 & 2.4 \\
\hline Silorane & 11.7 & 76 & 1.4 \\
\hline
\end{tabular}

\begin{tabular}{|c|c|c|}
\hline \multicolumn{2}{|r|}{ Table 2: Description of experimental groups and materials used } & Batch \\
\hline Flowable & $\begin{array}{c}\text { Flowable composite } \\
\text { (Clearfil Majesty }{ }^{\text {Ix }} \text { Flow; Kuraray Medical Inc., Okayama, Japan) }\end{array}$ & 0304BA \\
\hline Hybrid & $\begin{array}{l}\text { Inhomogeneous micro hybrid composite with pre-polymerized } \\
\text { homologous splinters } \\
\text { (Clearfil Majesty } \\
\text { hosterior; Kuraray Medical Inc., Okayama, Japan) }\end{array}$ & 0006CA \\
\hline Silorane & $\begin{array}{l}\text { Silorane-based composite } \\
\text { (Filtek }{ }^{\text {st }} \text { Silorane; 3M ESPE, Seefeld, Germany) }\end{array}$ & N391668 \\
\hline Control & $\begin{array}{l}\text { Natural teeth without any preparation } \\
\text { (Positive control for the fracture strength test) }\end{array}$ & \\
\hline $\begin{array}{c}\text { Adhesive } \\
\text { system }\end{array}$ & $\begin{array}{c}\text { Clearfil SE Bond } \\
\text { (Kuraray Medical Inc., Okayama, Japan) } \\
\text { Silorane System Adhesive - Bond, for Silorane group } \\
\left(\text { Filtek }{ }^{\text {N }} \text { Silorane; 3M ESPE, Seefeld, Germany) }\right.\end{array}$ & $\begin{array}{r}041780 \\
\text { N391668 }\end{array}$ \\
\hline
\end{tabular}


Switzerland). The cavities were subsequently sealed with a 2-step self-etching adhesive system (Clearfil SE Bond, Kuraray Medical Inc., Okayama, Japan). A $35 \% \mathrm{H} 3 \mathrm{PO} 4$ gel was used as an etching agent for $30 \mathrm{~s}$ on enamel only and rinsed off with a generous water spray. After careful drying of the cavities with a gentle air spray, the primer was applied for $20 \mathrm{~s}$ with a microbrush and gently air-dried. Then the bond was applied for $20 \mathrm{~s}$, gently air-dried and light-cured (Demi plus, 1100 $\mathrm{mW} / \mathrm{cm} 2$ to $1330 \mathrm{~mW} / \mathrm{cm} 2$, Kerr Corporation, Orange, USA) for 20 s. For the silorane group, the bond of silorane system adhesive (SSA) was then applied and light-cured (Demi plus, $1100 \mathrm{~mW} / \mathrm{cm} 2$ to 1330 $\mathrm{mW} / \mathrm{cm} 2$, Kerr Corporation, Orange, USA) for $20 \mathrm{~s}$ to avoid chemical incompatibility between the layer of SE Bond and silorane composite. There are two main reasons for use of the combination SE Bond and bond of SSA; in order to make the comparison of 3 different types of restorations possible, and because the interface primer-bond of SSA have shown nanoleakage in microtensile tests [21,22]. As a result, few attempts have been made to use the methacrylate adhesive for silorane restorations and acceptable results have been obtained when a hydrophobic resin coating layer, i.e. bond of SSA, was placed on top of the methacrylate adhesive layer $[23,24,25]$. Thus, this method was applied for the silorane group in this study. The cavities were then filled with the restorative materials (a hybrid, flowable and siloranebased composite) in two subsequent layers, light-cured (Demi plus, $1100 \mathrm{~mW} / \mathrm{cm} 2$ to $1330 \mathrm{~mW} / \mathrm{cm} 2$, Kerr Corporation, Orange, USA) for $40 \mathrm{~s}$ per layer. Finishing and polishing procedures were performed

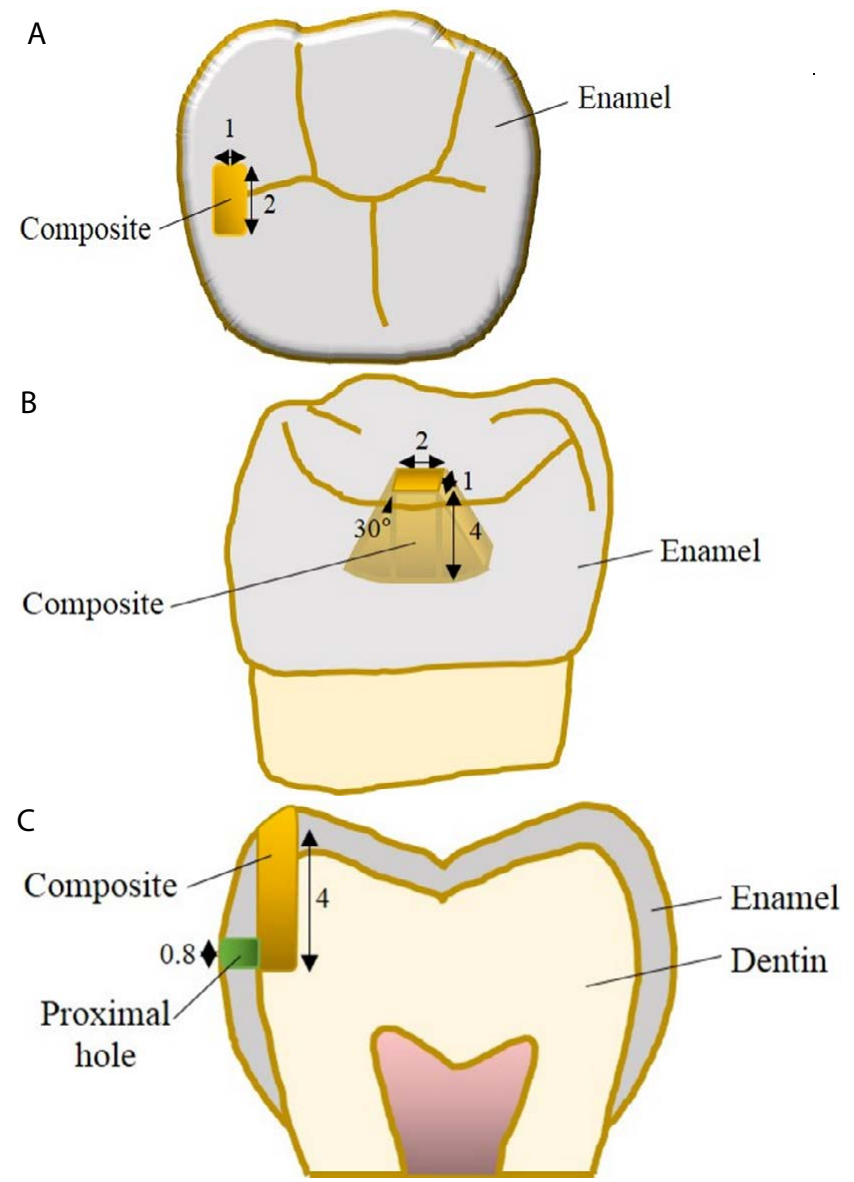

Fig. 1: Figures of cavity configuration: (a) occlusal view, (b) proximal view, (c) frontal view. Dimensions are in $\mathrm{mm}$. immediately after light curing with a $40 \mu \mathrm{m}$ point-ended pear bur (Intensiv SA, Grancia, Switzerland) and composite polishing points (Shofu Dental GmbH, Ratingen, Germany) with slight pressure with intermittent water spray under a 10x magnification. Then, to simulate proximal enamel carious lesion, a $0.8 \mathrm{~mm}$ diameter hole was prepared with a round bur (Intensiv SA, Grancia, Switzerland) through the enamel just beneath the proximal contact surface area (Fig. 1c). Restored molars were then maintained for 1 week in a moist atmosphere before mechanical loading.

All restored molars were submitted to 200'000 cycles of mechanical loading. The mechanical function of the device used in this study closely resembles to the one described by Krejci et al [26] (Figure. 2). The loading force generated by solenoids (Magnet AG, Hausen am Albis, Switzerland) was set at $50 \mathrm{~N}$ with a $1.5 \mathrm{~Hz}$ frequency, following a one-half sine wave curve. The maximal force was attained at the end of a $2.5 \mathrm{~mm}$ total course of the solenoid cores (including the first 1 $\mathrm{mm}$ free displacement). The restored molars remained immersed in a saline solution, at room temperature, during the entire test course. The position of the artificial cusps in the test chambers of the mechanical fatigue device was adjusted to maintain a $1 \mathrm{~mm}$ distance to the core top, allowing a free initial movement. The artificial cusps contacting the restored molars were made of stainless steel, with hardness similar to natural enamel (Vickers hardnesses: enamel $=320-325$; Actinit stainless steel $=315$ ). They were positioned to ensure a perpendicular contact with the restorations.

Before and after loading, restored molars were cleaned with toothpaste by using a rotating nylon brush and subsequently thoroughly rinsed in tap water. After careful drying, polyvinylsiloxane impressions (President light body, ColtèneWhaledent, Altstätten, Switzerland) were performed. Gold-sputtered resin replicas (Epofix,

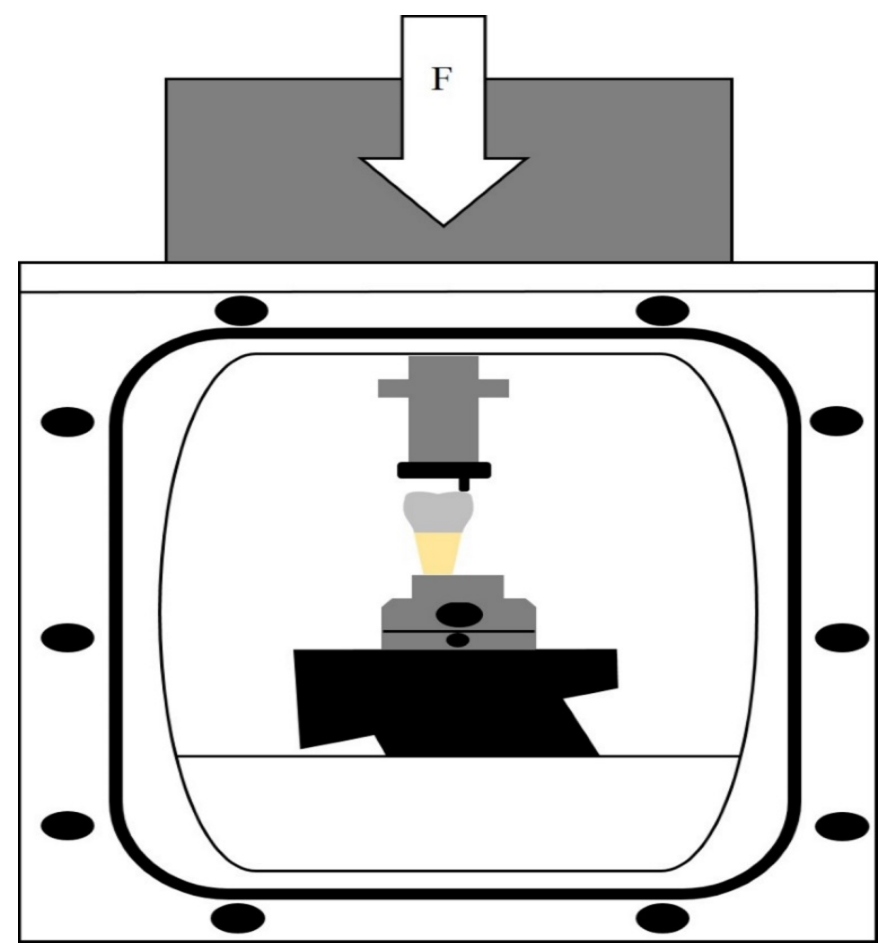

Fig. 2: Illustration of the mechanical loading device. 
Cho et al. (2020) Minimally invasive proximal cavities restored with a hybrid, flowable and low-shrinking composite: effect of marginal ridge preservation on failure pattern.

Struers, Rodrove, Denmark) were fabricated from these impressions and used for a quantitative analysis of the enamel-restoration adhesive interface, using a Scanning Electron Microscope (XL 20, Philips, Eindhoven, The Netherlands). The evaluation was performed at a standard 200x magnification. In order to standardize the assessment, the following parameters were considered: percentages of continuous margins (\%CM) and percentages of non-continuous margins $(\% \mathrm{NCM})$ either due to the presence of enamel fractures (\%NCM EF) or pure gaps (\%NCM PG).

The fracture resistance test was performed by using a universal testing machine (Instron, Model 1114, Instron Corp, High Wycombe, Great Britain) on the previously fatigued restored molars. Each tooth was inserted into a custom-made holding device, and a controlled load was applied using a stainless steel rod vertically to the longitudinal axis of the root. Pressure on the tip was applied at a crosshead speed of $1 \mathrm{~mm} / \mathrm{min}$ applied on the occlusal surface of the marginal ridge. All restored molars were loaded until fracture and the maximum breaking loads were recorded in Newtons (N).

\section{Statistical analysis}

All data was statistically evaluated by using SPSS for Macintosh. Differences in fracture strength \% of continuous margins, in \% of enamel fractures and in \% of pure gaps among the 3 groups were tested with ANOVA and Duncan post-hoc test at a level of confidence of $95 \%$

\section{Results}

The results of marginal adaptation (mean \pm standard deviation of $\% \mathrm{CM}, \% \mathrm{NCM}$ EF and \%NCM PG), both before and after loading, are presented in Table 3.

Before loading, the groups restored with flowable and silorane composite performed statistically similar and presented significantly higher \%CM than the one restored with the hybrid composite.

After loading, the groups restored with silorane and hybrid composite attained statistically similar \%CM and were significantly higher than the one restored with the flowable composite. The flowable group attained the lowest \%CM.

When comparing the results between intervals before-after loading, the group restored with flowable showed an important decrease of marginal adaptation. In this group, almost $50 \%$ of the margins were opened after loading, whereas hybrid group showed only a little decrease of $4.1 \%$.

In respect to the $\% \mathrm{NCM}$, enamel fractures were significantly more

\begin{tabular}{|c|c|c|c|c|c|c|}
\hline \multirow[t]{2}{*}{ Groups } & \multicolumn{2}{|c|}{$\begin{array}{c}\% \mathrm{CM} \\
\text { Mean } \pm \text { SD }\end{array}$} & \multicolumn{2}{|c|}{$\begin{array}{l}\% \text { NCM EF } \\
\text { Mean } \pm \text { SD }\end{array}$} & \multicolumn{2}{|c|}{$\begin{array}{l}\% \mathrm{NCM} \text { PG } \\
\text { Mean } \pm \text { SD }\end{array}$} \\
\hline & $\mathrm{BL}$ & $\mathrm{AL}$ & $\mathrm{BL}$ & $\mathrm{AL}$ & $\mathrm{BL}$ & $\mathrm{AL}$ \\
\hline Flowable & $95 \pm 5_{\mathrm{a}}$ & $53 \pm 24_{b}$ & $0_{a}$ & $3 \pm 6_{a}$ & $6 \pm 5$ & $41 \pm 20_{c}$ \\
\hline Hybrid & $85 \pm 11_{b}$ & $81 \pm 12_{a}$ & $10 \pm 10_{\mathrm{b}}$ & $12 \pm 9 \mathrm{~b}$ & $2 \pm 3 \mathrm{a}$ & $1 \pm 2 \mathrm{a}$ \\
\hline Silorane & $95 \pm 5 \mathrm{a}$ & $75 \pm 17_{a}$ & $1 \pm 3 \mathrm{a}$ & $4 \pm 9_{\mathrm{a}}$ & $3 \pm 3 a$ & $18 \pm 10_{\mathrm{b}}$ \\
\hline
\end{tabular}

present in margins of groups restored with the hybrid composite whereas pure gaps were typically observed in groups restored with the flowable and silorane composite.

Representative micrographs of the different marginal characteristics on each group, i.e. continuous margin, para-marginal enamel fracture and pure gaps are shown in Fig. 3.

The means with standard deviations of fracture resistance test on fatigued restored molars, as well as the minimum and maximum

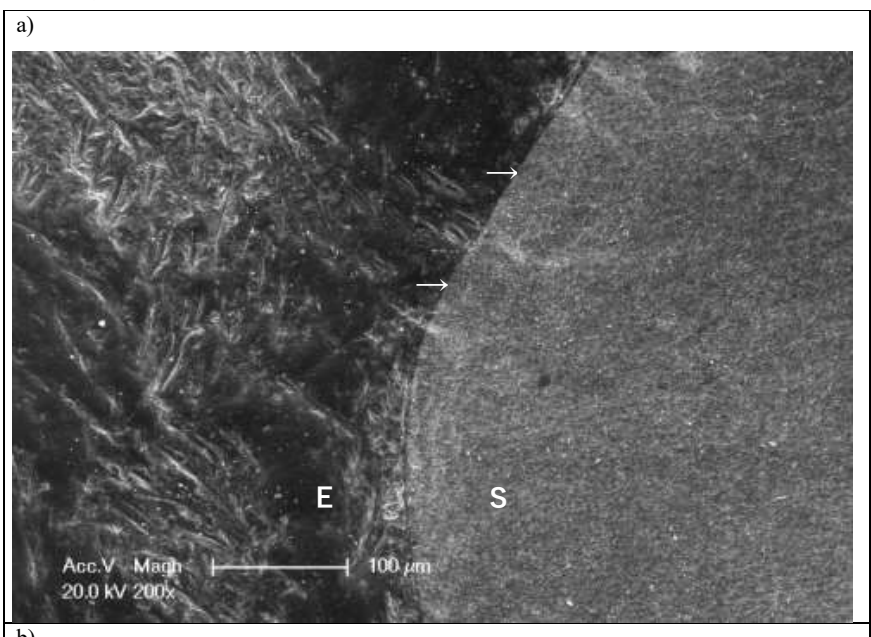
b)

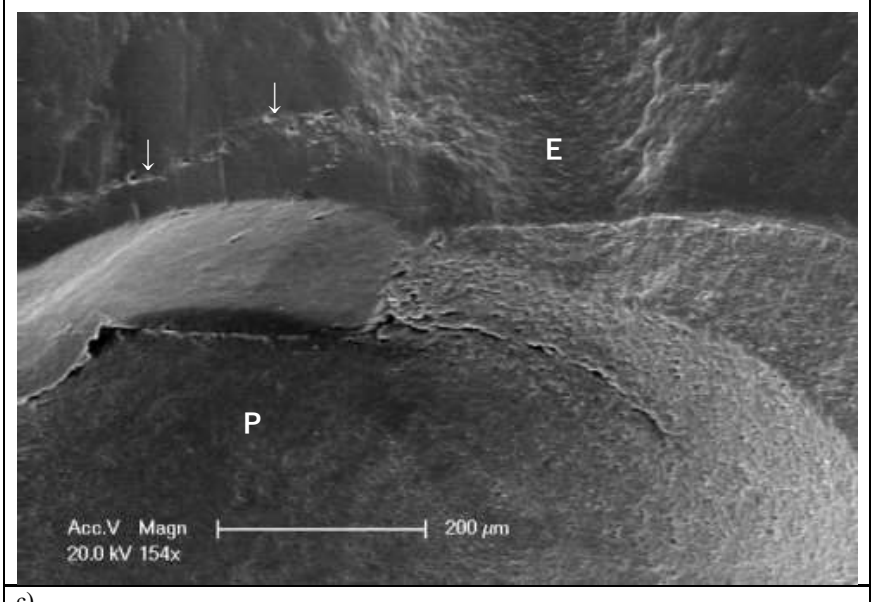
c)

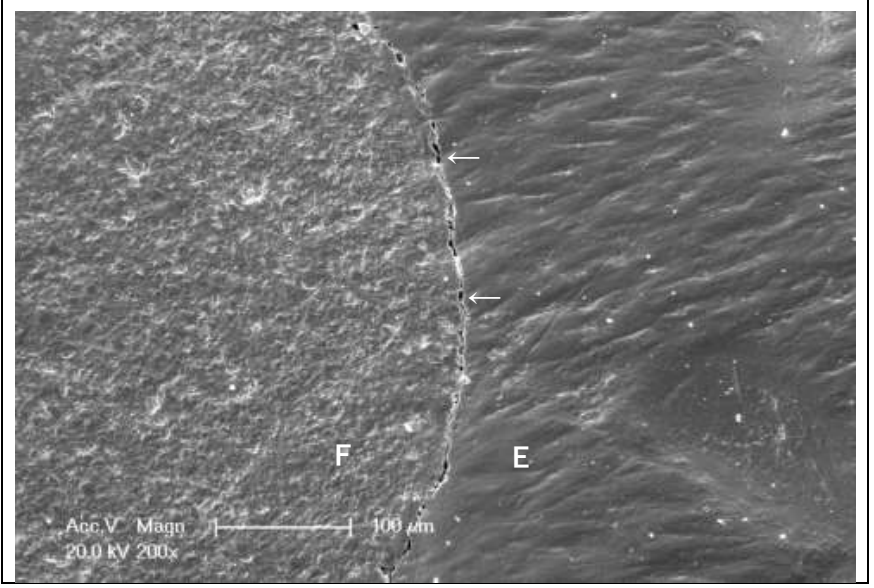

Fig. 3: Representative SEM micrographs of restorations' enamel-composite interface after loading. The arrows indicate: (a) continuous margin, (b) para-marginal enamel fracture, (c) pure gaps. ( $\mathrm{E}=$ enamel, $\mathrm{S}=$ silorane, $\mathrm{P}=$ hybrid composite, $\mathrm{F}=$ flowable composite). 
Cho et al. (2020) Minimally invasive proximal cavities restored with a hybrid, flowable and low-shrinking composite: effect of marginal ridge preservation on failure pattern.

\begin{tabular}{|c|c|c|c|}
\hline \multicolumn{4}{|c|}{$\begin{array}{c}\text { Table 4: Results of fracture resistance. Mean and SD expressed in Newtons. Minimum } \\
\text { and maximum loading forces registered for each group }\end{array}$} \\
\hline Groups & Mean \pm SD & Minimum & Maximum \\
\hline Flowable & $324 \pm 70_{\mathrm{b}}$ & 211 & 402 \\
\hline Hybrid & $296 \pm 89_{\mathrm{b}}$ & 169 & 398 \\
\hline Silorane & $251 \pm 93_{\mathrm{b}}$ & 76 & 362 \\
\hline $\begin{array}{c}\text { Control (non- } \\
\text { restored tooth) }\end{array}$ & $552 \pm 11_{\mathrm{a}}$ & 358 & 706 \\
\hline
\end{tabular}

forces registered during the fracture test are presented in Table 4. No significant differences in fracture strength were detected between the three restored groups. A significantly higher fracture strength was observed in the non-restored group control, that is, the one in which the marginal ridge was intact.

The typical stress-strain curves for brittle and elastic materials [27] were used for comparison with each group during the fracture test, figure 4 (a to d) for the flowable, silorane, hybrid and control group, respectively. It was interesting to see that although no significant differences in fracture strength were observed among the three materials, the shape of the stress-strain curve was specific for each group. The profile of the stress-strain curves in the flowable group (Fig. 4a) evidenced a material poorly ductile (represented by a short length of the horizontal line within the curve which shows that the material can be extended but does not show plastic deformation). A similar behavior was observed in the silorane group (Fig. 4b). Conversely, the curves of the hybrid composite (Fig. 4c) evidenced a slightly more elastic behavior (represented by a long horizontal line within the curve which shows the plastic deformation of the material) before fracturing. Finally, the curve profiles of the control group (Fig. $4 \mathrm{~d}$ ) were typical of a stiff material (represented by a steep gradient of the curve) like enamel.

\section{Discussion}

This study was designed to understand how different categories of composite materials, when used in the ultraconservative occlusal fossa cavity, influence the mechanical behavior of these restorations. Its main purpose was to assess which type of material may be most suitable for the minimally invasive restorations of proximal caries. For this purpose, the study design included three materials with different mechanical properties, which would explain the diversity obtained in our results (Table 1). In addition, cavities with a high C-factor were prepared to enable the behavioral comparison of three different materials in extremely difficult conditions concerning contraction stresses. The marginal ridge fracture strength was an important evaluation criteria, especially in comparison with the control group, as it was pointed out to be the main failure cause in occlusal fossa restorations. Nonetheless, the secondary decay and cavitation in enamel were revealed as other principal failure origin in clinical trials [7], therefore the assessment of marginal adaptation before and after mechanical loading was performed as well. The carious lesions were simulated by a cavity which was drilled into the proximal wall. We found that this was the only way to simulate proximal enamel demineralization, given the fact that there is no available technique to reproduce artificial carious lesions through the enamel; a recent study showed that the deepest subsurface lesion produced had a mean depth of 86 micrometer [28].

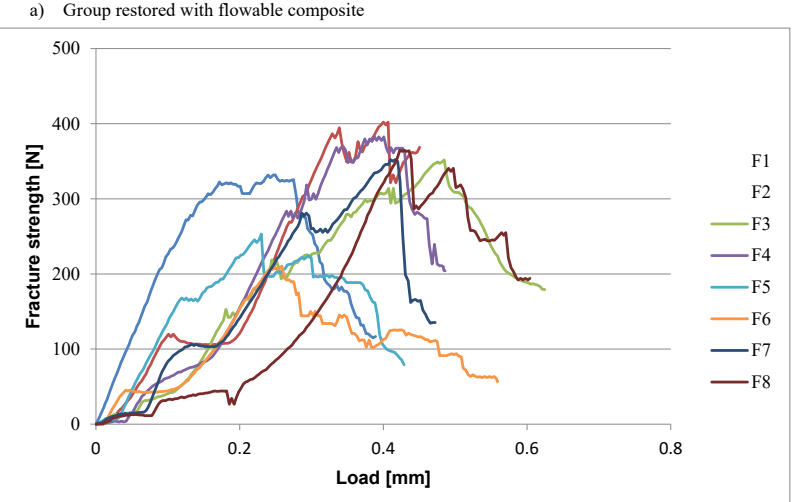

b) Group restored with silorane composite

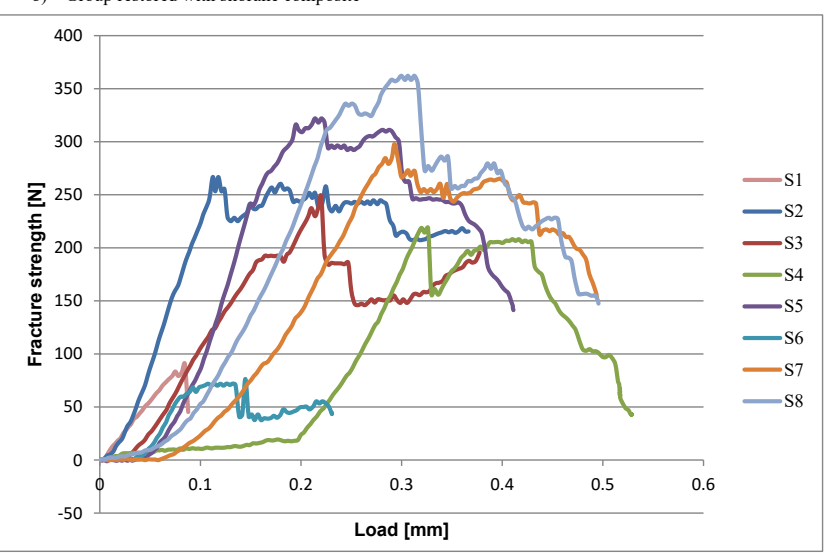

c) Group restored with hybrid composite

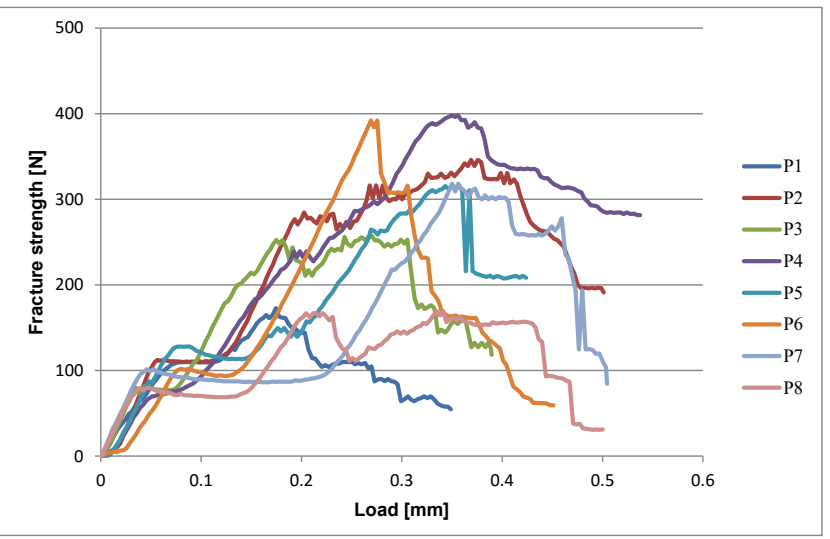

d) Non-restored group (control)

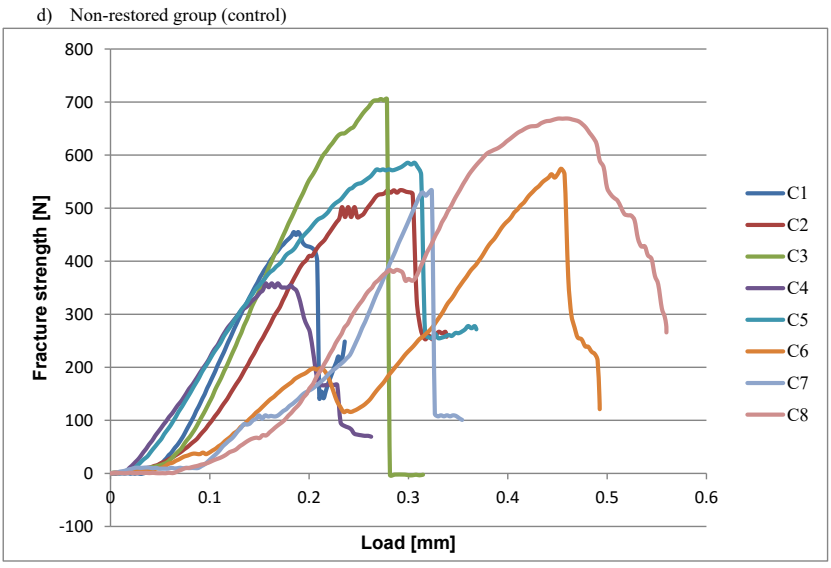

Fig. 4: Stress-strain curves of the 4 groups. 


\section{Marginal adaptation}

As statistically significant differences of marginal adaptation rate could be demonstrated between groups, before and after mechanical loading, the first null hypothesis could be rejected. These findings can be explained by differences in the modulus of elasticity (E) and polymerization contraction between materials.

During polymerization, the resin composite contracts and generates stresses at the adhesive interface. These stresses are accompanied by undesirable consequences, such as deformation of the tooth's cusps, gap formation, and/or para-marginal enamel fractures $[29,30]$. A stiff restorative material induces more tooth deformation and increases pre-loading stress following polymerization contraction $[31,32]$, which can lead to an immediate margin failure, as it was the case in the hybrid group.

The polymerization contraction undergoes two phases: the phase before and the phase after the gel point. During the first phase, the resin retains its capacity to flow, and therefore, it compensates the contraction forces by rearrangement of the molecules by preventing strain that would otherwise develop at the interfaces [33]. When the gel point is reached, stress is transmitted from the composite toward surrounding bonded structure; the contraction must be compensated by strain of the composite, tooth or adhesive [27]. If the stress surpass the low tensile strength of enamel $(10 \mathrm{MPa})$ [34], para-marginal enamel fracture appears. For reference, the average bond strength is 15-40 MPa [35].

On the contrary, a low-elastic modulus composite, thanks to its elasticity, induces less tooth deformation, thus less pre-loading stress. Reduced E-modulus leads to reduced gap formation [36]. That is why good marginal adaptation could be observed in flowable and silorane groups before loading. Moreover, flowable composites are considered to wet the cavity better than restorative composites due to their flowability, to have thus a better adaptation to the dental surface [37]. And compared to the commercial methacrylate-based composite, the time of gelation of silorane is found to be significantly longer [38]; it decreases the contraction stress and consequently better interfacial integrity scores could be expected $[39,40]$.

As already mentioned, the hybrid composite used in our trial was a stiff material. A higher filler load would lead to an increase in stiffness [41] and generally, it may reduce the overall contraction of composites due to less molecules available for the polymerization reaction [42]. This means, in the contrary, an elastic material like flowable composite would suffer more from polymerization contraction, leading to prestressed obturations which allows for more marginal failure under occlusal load $[36,43,44]$. Moreover, the displacement of cusp under load is inversely proportional to composites' rigidity [45]. It is in accordance with the results of our trial, where the hybrid group showed better behavior after loading than the flowable group which presented a drastic change. And it should be noted that the silorane group, after loading, had better behavior than the flowable group despite their similar elasticity. Low polymerization contraction of silorane could lead to less pre-stressed obturations than flowable material.

Overall, material chemico-mechanical properties (such as filler/matrix and consequently the material's elasticity/rigidity and viscosity) proved to influence the marginal adaptation before and after loading, probably because it has impacts on tooth deformation and stress development. And satisfactory initial marginal adaptation didn't necessarily predict an optimal functional behavior, as shown by the results of flowable group which showed a sufficiently high score in marginal adaptation before loading but incurred a drastic reduction in marginal adaptation after loading. These results are in agreement with a recent review [46]. Elasticity and polymerization contraction have two opposite effects. The benefits of the elasticity of the flowable composite are probably surpassed by its contraction [33]. And at the use of hybrid composite, a certain degree of initial stress should be accepted in order to guarantee sufficient rigidity to the restoration, particularly since para-marginal enamel fractures could present less serious consequences for the longevity of the restorations than pure gaps [32]. According to the literature, there is a general agreement on the fact that a high E-modulus composite (15-20 GPa) would minimize marginal deterioration of restorations under loading and therefore perform well clinically $[36,47,48]$.

Fracture resistance of marginal ridge

The second null hypothesis could be accepted hence no significant differences in fracture strength were noticed within the restored groups, with exception for the group control; it appeared that the marginal ridge strength of restored teeth were significantly reduced in comparison to those of intact teeth. It is difficult to compare these findings with other studies as the experimental set-up in terms of method and materials used are diverse. But considering this fact, abovementioned results are in accordance with Purk's findings [49] but diverge from other studies where they found no difference in strength of the tunnel prepared and restored teeth and that of sound teeth [8,50-52]. Another author found that a conservative tunnel restoration situated $2 \mathrm{~mm}$ from the marginal ridge, does not significantly weaken an otherwise intact tooth [50]. And other researches showed that tooth with tunnel preparation could be reinforced when restored with composite resin, compared to cavity prepared but non restored or cermet restored tooth $[49,50]$.

Given that average masticatory force on a single tooth is 39-146 $\mathrm{N}$ depending on the type of food [53-55] and the forces exerted in normal chewing on the occlusal surface seldom exceed 45-60 N [56], mean fracture strength values obtained in all three restored groups showed sufficient reinforcement of resistance to normal masticatory function. Additionally, a study demonstrated that strains in the vicinity of marginal ridges are lower than near the cementenamel junction, hence the marginal ridges are not highly stressed areas during simulated occlusal loading [57]. The high SD could be explained by the use of non-homogeneous samples, which were natural human teeth. Although each tooth was carefully examined prior to restoration in order to detect enamel fracture lines near to the proximal ridges, variations in tooth morphology like enamel fracture lines might have influenced the results to some extent. Enamel cracks are a regular occurrence in mature human enamel and an experimental study confirmed the importance of margin cracks as a potential source of tooth failure [58]. 
Cho et al. (2020) Minimally invasive proximal cavities restored with a hybrid, flowable and low-shrinking composite: effect of marginal ridge preservation on failure pattern.

Despite laboratory testing set-up, investigated samples and experiment protocols could influence the results, in-vitro models allow to test in a controlled way hypotheses that would be unviable to test invivo [32]. But these results have to be interpreted with caution due to an extreme cavity design as a "hole" was made in the proximal enamel to simulate demineralization. Possibly, enamel and dentin removal was more pronounced in respect to a real demineralization lesion, and this could have adversely affected the results. This may explain why fracture strength of all restored groups was significantly lower than the nonrestored control group. Nevertheless, this "worst case scenario" served to demonstrate that even in cases in which tooth substance is removed below the marginal ridge, restorative procedures with composite are able to provide sufficient reinforcement of restored teeth to normal masticatory function and withstand fatigue test. For example, the hybrid composite used in this study delivered a \%CM above $80 \%$ after loading, which is considered a sufficiently high score. Additionally, it should be emphasized that marginal integrity and resistance of enamel ridge are not the only parameters implicated in clinical success. Other factors such as retention, marginal and surface discoloration, anatomic form, para-functional forces and secondary caries may influence, clinically, the long-term behavior of this type of restorations. In this sense, future studies should evaluate these parameters on other composite materials than the ones used in this study, to determine if this restorative technique can be validated for clinical use.

\section{Conclusions}

Under the conditions of the present in-vitro study, the ultraconservative occlusal fossa technique may be a valid alternative to conventional class II restorations if used after a careful case selection. The first null hypothesis could be rejected; the hybrid composite and silorane material provided the highest percentages of continuous margin after fatigue test. The flowable material produced marginal failures under load, probably due to a lower elastic modulus and a higher contraction force in respect to the other materials. The second null hypothesis could be accepted; while no statistically significant differences in fracture strength were found amongst groups except for control, the hybrid group showed a trend to a slightly more ductile behavior i.e. better capacity for elastic deformation.

\section{Reference}

1. Black GV (1891) Management of enamel margins. Dent Cosmos 33: 85-100.

2. Reeh ES, Messer HH, Douglas WH (1989) Reduction in tooth stiffness as a result of endodontic and restorative procedures. J Endod 15: 512-516. [crossref]

3. Lussi A, Gygax M (1998) Iatrogenic damage to adjacent teeth during classical approximal box preparation. J Dent 26: 435-441. [crossref]

4. Medeiros VA, Seddon RP (2000) Iatrogenic damage to approximal surfaces in contact with class II restorations. J Dent 28: 103-110. [crossref]

5. Qvist V, Johannessen L, Bruun M (1992) Progression of approximal caries in relation to iatrogenic preparation damage. J Dent Res 71: 1370-1373. [crossref]

6. Gilmore N, Sheiham A (1971) Overhanging dental restorations and peridontal disease. J Periodontol 42: 8-12. [crossref]

7. Hasselrot L (1998) Tunnel restorations in permanent teeth. A 7 year follow up study Swed Dent J 22: 1-7. [crossref]

8. Kielbassa AM, Müller J, Gernhardt CR (2009) Closing the gap between oral hygiene and minimally invasive dentistry: A review on the resin infiltration technique of incipient (proximal) enamel lesions. Quintessence Int 40: 663-681. [crossref]
9. Tyas MJ, Anusavice KJ, Frencken JE, Mount GJ (2000) Minimal intervention dentistry- a review. Int Dent J 50: 1-12. [crossref]

10. Wiegand A, Attin T (2007) Treatment of proximal caries lesions by tunnel restorations. Dent Mater 23: 1461-1467. [crossref]

11. Papa J, Cain C, Messer HH, Wilson PR (1993) Tunnel restorations versus class II restorations for small proximal lesions: A comparison of tooth strengths. Quintessence Int 24: 93-98. [crossref]

12. Mount GJ (2003) Minimal intervetion dentistry: Rationale of cavity design. Oper Dent 28: 92-99. [crossref]

13. Ardu S, Perroud R, Krejci I (2006) Extended sealing of interproximal caries lesions. Quintessence Int 37: 423-427. [crossref]

14. Strand GV, Nordbø H, Tveit AB et al (1996) A 3-year clinical study of tunnel restorations. Eur J Oral Sci 104:384-389. [crossref]

15. Peters MC, McLean ME (2001) Minimally invasive operative care. I. minimal intervention and concepts for minimally invasive cavity preparations. J Adhes Dent 3:7-16. [crossref]

16. Wilson AD, McLean JW (1988) Glass-ionomer cement. Quintessence Publishing Co Chicago.

17. Hunt PR (1984) A modified class II cavity preparation for glass ionomer restorative materials. Quintessence Int 15: 1011-1018. [crossref]

18. Strand GV, Nordbø H, Leirskar J, von der Fehr FR, Eide GE (2000) Tunnel restorations placed in routine practice and observed for 24 to 54 months. Quintessence Int 31: 453460. [crossref]

19. Hasselrot L (1993) Tunnel restorations. Swed Dent J 17: 173-182.

20. Versluis A, Tantbirojn D, Douglas WH (1998) Do dental composites always shrink toward the light? J Dent Res 77: 1435-1445. [crossref]

21. Mine A, De Munck J, Van Ende A, Cardoso MV, Kuboki T et al. (2010) TEM characterization of a silorane composite bonded to enamel/dentin. Dent Mater 26: 524-532. [crossref]

22. Duarte S, Phark JH, Varjao FM, Sadan A (2009) Nanoleakage, ultramorphological characteristics, and microtensile bond strengths of a new low-shrinkage composite to dentin after artificial aging. Dent Mater 25: 589-600. [crossref]

23. Ivanovas S, Hickel R, Ilie N (2010) How to repair fillings made by silorane-based composites. Clin Oral Invest 16: 102-105.

24. Samimi P, Alizadeh V, Fathpour K, Mazaheri H, Mortazavi V (2016) In-vitro comparison of the effect of different bonding strategies on the micro-shear bond strength of a silorane-based composite resin to dentin. Dent Res J (Isfahan) 13: 124131. [crossref]

25. Tezvergil-Mutluay A, Lassila LV, Vallittu PK (2008) Incremental layers bonding of silorane composite: The initial bonding properties. J Dent 36: 560-563. [crossref]

26. Krejci I, Reich T, Lutz F, Albertoni M (1990) In-vitro testverfahren zur evaluation dentaler restaurationssysteme. Schweiz Monatsschr Zahnmed 100: 953-960. [crossref]

27. Darvell BW (2009) Materials Science for dentistry, 9th edn. CRC Press, Cambridge, chapter 1, page 16 .

28. Magalhães AC, Moron BM, Comar LP, Wiegand A, Buchalla W et al. (2009) Comparison of cross-sectional hardness and transverse microradiography of artificial carious enamel lesions induced by different demineralising solutions and gels. Caries Res 43: 474-483. [crossref]

29. Ferracane JL (2005) Developing a more complete understanding of stresses produced in dental composites during polymerization. Dent Mater 21: 36-42. [crossref]

30. Garcia-Godoy F, Krämer N, Feilzer A, Frankenberger R (2010) Long-term degradation of enamel and dentin bonds: 6-year results in vitro vs. in vivo. Dent Mater 26: 1113-1118. [crossref]

31. Arola D, Galles LA, Sarubin MF (2001) A comparison of the mechanical behavior of posterior teeth with amalgam and composite MOD restorations. J Dent 29: 63-73. [crossref]

32. Benetti AR, Peutzfeldt A, Lussi A, Flury S (2014) Resin composites: Modulus of elasticity and marginal quality. J Dent 42: 1185-1192. [crossref]

33. Pecie R, Onisor I, Krejci I, Bortolotto T (2013) Marginal adaptation of direct class II composite restorations with different caity liners. Oper Dent 38: E210-220. [crossref] 
Cho et al. (2020) Minimally invasive proximal cavities restored with a hybrid, flowable and low-shrinking composite: effect of marginal ridge preservation on failure pattern.

34. Bowen RL, Rodriguez MS (1962) Tensile strength and modulus of elasticity of tooth structure and several restorative materials. J Am Dent Assoc 64: 378-387. [crossref]

35. De Munck J, Van Landuyt K, Peumans M, Poitevin A, Lambrechts P et al. (2005) A critical review of the durability of adhesion to tooth tissue: Methods and results. $J$ Dent Res 84: 118-132. [crossref]

36. Asmussen E, Peutzfeldt A (2008) Class I and class II restorations of resin composite: An FE analysis of the influence of modulus of elasticity on stresses generated by occlusal loading. Dent Mater 24: 600-605. [crossref]

37. Chuang SF, Jin YT, Liu JK, Chang CH, Shieh DB (2004) Influence of flowable composite lining thickness on class II composite restorations. Oper Dent 29: 301-308. [crossref]

38. Ilie N, Hickel R (2011) Investigations on a methacrylate-based flowable composite based on SDR $^{\mathrm{m}}$ technology. Dent Mater 27: 348-355. [crossref]

39. Feilzer AJ, De Gee AJ, Davidson CL (1993) Setting stresses in composites for two different curing modes. Dent Mater 9: 2-5. [crossref]

40. Feilzer AJ, De Gee AJ, Davidson CL (1990) Quantitative determination of stress reduction by flow in composite restorations. Dent Mater 6: 167-171. [crossref]

41. Masouras K, Silikas N, Watts DC (2008) Correlation of filler content and elastic properties of resin-composites. Dent Mater 24: 932-939. [crossref]

42. Miyazaki M, Hinoura K, Onose H, Moore BK (1991) Effect of filler content of lightcured composites on bond strength to bovine dentine. J Dent 19: 301-303. [crossref]

43. Ausiello P, Apicella A, Davidson CL, Rengo S (2001) 3D-finite element analyses of cusp movements in a human upper premolar, restored with adhesive resin-based composites. J Biomech 34: 1269-1277. [crossref]

44. Lutz F, Krejci I, Barbakow F (1991) Quality and durability of marginal adaptation in bonded composite restorations. Dent Mater 7: 107-113. [crossref]

45. Ausiello P, Rengo S, Davidson CL, Watts DC (2004) Stress distributions in adhesively cemented ceramic and resin-composite class II inlay restorations: A 3D-FEA study. Dent Mater 20: 862-872. [crossref]

46. Dietschi D, Argente A, Krejci I, Mandikos M (2013) In vitro performance of class I and II composite restorations: A literature review on nondestructive laboratory trials--part II. Oper Dent 38: E182-200. [crossref]
47. Dietschi D, Argente A, Krejci I, Mandikos M (2013) In vitro performance of class I and II composite restorations: A literature review on nondestructive laboratory trials--part I. Oper Dent 38: E166-181. [crossref]

48. Lambrechts P, Braem M, Vanherle G (1987) Evaluation of clinical performance for posterior composite resins and dentin adhesives. Oper Dent 12: 53-78. [crossref]

49. Purk JH, Eick JD, Roberts M, Chappell RP, Moore DL (1990) Fracture strength of class I versus class II restored premolars tested at the marginal ridge. 2. cavosurface bonding and cavosurface plus internal enamel bonding. Quintessence Int 21: 655-662. [crossref]

50. Covey D, Schulein TM, Kohout FJ (1989) Marginal ridge strength of restored teeth with modified class II cavity preparations. J Am Dent Assoc 118: 199-202. [crossref]

51. Fasbinder DJ, Davis RD, Burgess JO (1991) Marginal ridge strength in class II tunnel restorations. Am J Dent 4: 77-82. [crossref]

52. Ramírez-Sebastià A, Bortolotto T, Cattani-Lorente M, Giner L, Roig M et al. (2014) Adhesive restoration of anterior endodontically treated teeth: Influence of post length on fracture strength. Clin Oral Investig 18: 545-554. [crossref]

53. Duyck J, Van Oosterwyck H, De Cooman M, Puers R, Vander Sloten J et al. (2000) Three-dimensional force measurements on oral implants: A methodological study. J Oral Rehabil 27: 744-753. [crossref]

54. Howell AH, Brudevold F (1950) Vertical forces used during chewing of food. J Dent Res 29: 133-136. [crossref]

55. Howell AH, Manly RS (1948) An electronic strain gauge for measuring oral forces. $J$ Dent Res 27: 705-712.

56. De Boever JA, McCall WD Jr, Holden S, Ash MM Jr (1978) Functional occlusal forces: An investigation by telemetry. J Prosthet Dent 40:326-333. [crossref]

57. Palamara JEA, Palamara D, Messer HH (2002) Strains in the marginal ridge during occlusal loading. Aust Dent J 47: 218-222. [crossref]

58. Chai H, Lee JJ, Kwon JY, Lucas PW, Lawn BR (2009) A simple model for enamel fracture from margin crackss. Acta Biomater 5: 1663-1667. [crossref] 